\title{
Overall survival of classical Hodgkin's lymphoma in Saudi patients is affected by XPG repair gene polymorphism
}

\author{
HUDA AL SAYED AHMED ${ }^{1}$, WASIM FAWZI RASLAN ${ }^{1}$, \\ ABDEL HALIM SALEM DEIFALLA $^{2}$ and MOHAMMAD DAHMANI FATHALLAH ${ }^{3}$ \\ ${ }^{1}$ Pathology Services Division and Laboratory Department, Johns Hopkins Aramco Healthcare, Dhahran 34465, \\ Kingdom of Saudi Arabia; ${ }^{2}$ Department of Anatomy, College of Medicine and Medical Sciences and \\ ${ }^{3}$ Department of Higher Studies, Arabian Gulf University, Manama 26671, Kingdom of Bahrain
}

Received May 11, 2018; Accepted October 23, 2018

DOI: $10.3892 /$ br.2018.1165

\begin{abstract}
In Hodgkin's lymphoma (HL), single nucleotide polymorphisms (SNPs) of specific DNA repair genes have been identified to have an important role in the risk of HL. Consequently, they may also serve an important role in HL prognosis and disease outcome. The present study aimed to define an SNP molecular profile, based on DNA repair genes mutations, as predictive biomarkers for the prognostic outcome of patients with Classical HL (CHL) in Saudi Arabia. Genotyping of selected SNPs located in selected DNA repair genes was performed on $100 \mathrm{CHL}$ cases and an equivalent number of healthy controls. No significant associations between CHL disease relapse (DR) or overall survival (OS) and 4 DNA repair genes were observed, with the exception of xeroderma pigmentosum, complementation group G (XPG) repair gene SNP (rs17655), which revealed a statistically significant association with $\mathrm{CHL}$ patient survival $(P=0.036)$. Accordingly, these data suggest that the XPG gene may be a useful predictive molecular genetic biomarker for CHL clinical outcome. The present study also provided valuable insights on the contribution of DNA repair genes in Saudi patients with CHL. To the best of our knowledge, we defined for the first time, a specific genetic pattern associated with CHL outcome was defined in the present study in Saudi patients.
\end{abstract}

\section{Introduction}

Hodgkin's lymphoma (HL) is a tumor that has a characteristic pathological behavior and requires specific careful

Correspondence to: Dr Huda Al Sayed Ahmed, Pathology Services Division and Laboratory Department, Johns Hopkins Aramco Healthcare, 6th Street, Dhahran, Aramco Gharb Al, Dhahran 34465, Kingdom of Saudi Arabia

E-mail: huda.alsayedahmed@jhah.com

Key words: classical Hodgkin's lymphoma, single nucleotide polymorphism, DNA repair genes, predictive biomarkers, single nucleotide polymorphism analysis molecular profile clinical management. Our understanding of the epidemiological behavior of HL is constantly updated and data are available for different regions; however, studies from the kingdom of Saudi Arabia are scarce (1). At present, genetic signatures identified through genetic screening are a method of predicting and monitoring cancer prognosis by identifying patterns in molecular genetics demonstrated to be associated with a particular type of cancer $(2,3)$. Previous findings have indicated that patients with HL with unfavorable outcomes exhibited higher levels of genetic instability compared with other types of cancer (4). Indeed, HL incidence has increased over the previous decade among the Cooperation Council for the Arab States of the Gulf (5). However, a systematic analysis for the global burden of disease revealed that, despite the increase in the incidence of all types of cancer, HL-associated mortalities had decreased between 2005 and 2015 (6). Based on data from Al-Diab et al (7) on Saudi and Middle Eastern populations, there is an elevated incidence of HL, particularly in the younger age group of 12-40 years. This study hypothesized that the rapid improvement in the living standards and healthcare systems during the previous 2 decades has affected the epidemiology of HL. In the Middle East and Asia, HL is more common during childhood compared with Western countries, where its peak incidence is in patients between 10 and 30 years old (8). A revised European-American Lymphoma classification, which was adopted later by the World Health Organization, uses morphologic, phenotypic, genotypic and clinical data for the classification of HL (8). It encompasses two well defined entities: Nodular lymphocyte predominant HL and the classical HL (CHL). CHL comprises $~ 95 \%$ of HL cases worldwide (8).

Hodgkin Reed-Sternberg cells are surrounded by a number of non-neoplastic immune cell subsets, which represent the tumor microenvironment (TME) and typically dominates the cellular milieu. However, the overall genetic expression profile in an individual will contain a combination of the gene expression patterns of the separate variable cellular components of the TME, and that of the tumor cells (9). Studies of candidate single nucleotide polymorphisms (SNPs) to identify HL risk factors may be useful. Unless future studies employ adequate sample sizes to reflect the etiological heterogeneity within 
HL, identifying genotypes according to patient age and tumor histology is essential (10). DNA mutation or damage of DNA repair genes will subsequently decrease genomic integrity and stability. Few studies have described an association between defective proteins in DNA repair pathways and susceptibility to HL.

The DNA repair mechanism is genetically regulated, and variation in the repair capacity was observed based on SNPs in DNA repair genes (11). Several epidemiological studies have identified hundreds of these SNPs, and suggested a wide population variability in the DNA repair process, with potential associations with higher risk of cancer and hematological malignancies $(4,11)$. A polymorphism in the DNA repair gene may modulate the DNA repair gene phenotype, particularly if these SNPs exist within the regulatory region that alters the protein expression, and consequently the functional properties of the repair enzymes (11). At present, the effect of these SNPs on altering the risk of HL has not been investigated widely. Monroy et al (4) evaluated the gene-gene interaction between candidate genes in direct reversal, nucleotide excision repair (NER), base excision repair (BER) and double strand break (DSB) pathways.

The X-ray repair cross-complementing (XRCC) gene is involved in the repair of single strand DNA breaks created as a result of exposure to ionizing radiation or alkylating agents. This protein is active in the base excision repair (BER) pathway (4). A micro satellite polymorphism in this gene was identified to be associated with increased risk of cancer in patients with radio sensitivity (4). Specifically, the XRCC1 gene is involved in the BER pathway and is responsible for repairing oxidizing and alkylating DNA lesions. The XRCC3 gene is important for maintaining chromosome stability. In addition, this gene complements a repair deficient mutant that is sensitive to numerous DNA damaging agents and is unstable. The XRCC3 gene is involved in the DSB recombination repair pathway and is able to restore DNA through a recombination process between the damaged strand and the homologous copy of the gene (4). XRCC3 (Thr241Met), XRCC1 (Arg194Trp) and XRCC1 (Arg399Gln) polymorphisms serve a role in modulating the risk of HL (4). In addition, the cumulative genetic risk score revealed a significant risk of HL with an increased number of gene polymorphisms involved in BER and DSB (4). The XRCC gene SNPs result in an amino acid substitution, which affects the structure and function of the final intended protein (11), and thereafter may affect the risk stratification or prognosis of the HL.

The xeroderma pigmentosum, complementation group C (XPC) gene encodes for a protein that is a component of the NER pathway. Concurrently, the XP complementation group $\mathrm{G}$ (XPG) gene encodes for a specific single strand DNA endonuclease enzyme that enables the 3 ' incision step in the DNA excision repair pathway to repair UV-induced damage. Mutations in the XP gene may result in xeroderma pigmentosum, with a susceptibility to early development of carcinomas (11). In HL, previous study has investigated the correlation between HL risk and polymorphisms in DNA repair protein XP group C, D and G (11). XPC, also known as transmembrane Protein 43, XPD, also known as group 2 excision repair cross-complementing, and XPG genes participate in the NER pathway, which is responsible for repairing bulky
DNA adducts and helix-distorting lesions (11). A previous study observed that allelic variants in the mutant DNA repair protein XPC, in particular XPC Ala499Val, were directly associated with HL risk (4). Nevertheless, El-Zein et al (11) identified a direct association between the XRCC1 gene polymorphism Arg399Gln and the risk of HL. Conversely, analysis of the combined effect of XRCC1/XRCC3 and XRCC1/XPC polymorphisms identified a significant association with the risk of HL (11). In addition, gene variants in XRCC1 Gln/Gln, XRCC3 Thr/Thr and XRCC1 Arg/Gln, collectively with XPC Lys/Lys, led to a significant rise in the risk of the HL (11).

In the present study, the aim was to define an SNP molecular profile, based on DNA repair genes mutations, as a predictive biomarker for the prognosis of CHL patients in Saudi Arabia. This was achieved through analyzing gene expression by polymerase chain reaction and determining associations with disease relapse and overall survival of the CHL cohort.

\section{Materials and methods}

Sample collection. The present study was a retrospective case-control study in which formalin-fixed paraffin embedded (FFPE) tissue samples from patients with CHL were studied. A total of 100 FFPE samples from patients diagnosed with CHL from January 1990 to December 2015 were obtained. Samples from all the histological CHL sub classes and stages were included, according to the World Health Organization scheme, which sub classifies CHL into four subtypes: Nodular sclerosis (NS), mixed cellularity (MC), lymphocyte depleted (LD) and lymphocyte rich (LR) $(12,13)$. Diagnosing HL is recommended followed staging, and is made according to the Ann Arbor staging scheme or its Cotswold modification. In the present study the latter was used to classify HL as low grade (stage I or II) and high grade (stage III or IV) (14).

Patient tissue samples were recruited to examine 4 different DNA repair gene SNPs (2 XRCC1 SNPs, XRCC3, 2 XPC SNPs and XPG) using a polymerase chain reaction (PCR) assay. DNA repair gene information is presented in Table I.

Concomitantly, peripheral blood (PB) samples were collected from normal healthy blood donors, with no known personal or family history of cancer, to be used as the 'study control group'. In addition to the study control group, 2 normal fresh tonsil tissues were obtained to serve as 'CHL negative controls' (i.e., negative for HL). A total of 2 fresh lymph node tissues from newly-diagnosed patients with CHL were also obtained to serve as 'CHL positive controls' (i.e., positive for the presence of $\mathrm{HL}$ ).

Ethical approval was obtained from the Institutional Review Board at John Hopkins Aramco Healthcare Center (JHAH) (Dhahran, Saudi Arabia) and from the Research and Ethics Committee at Arabian Gulf University (Manama, Bahrain). All subjects providing control tissues gave written informed consent.

Deparaffinization of FFPE tissue samples and DNA extraction for molecular PCR. Total genomic DNA was extracted from the paraffin-embedded patient tissues, control group tissues and the study control group PB samples using QIAamp 


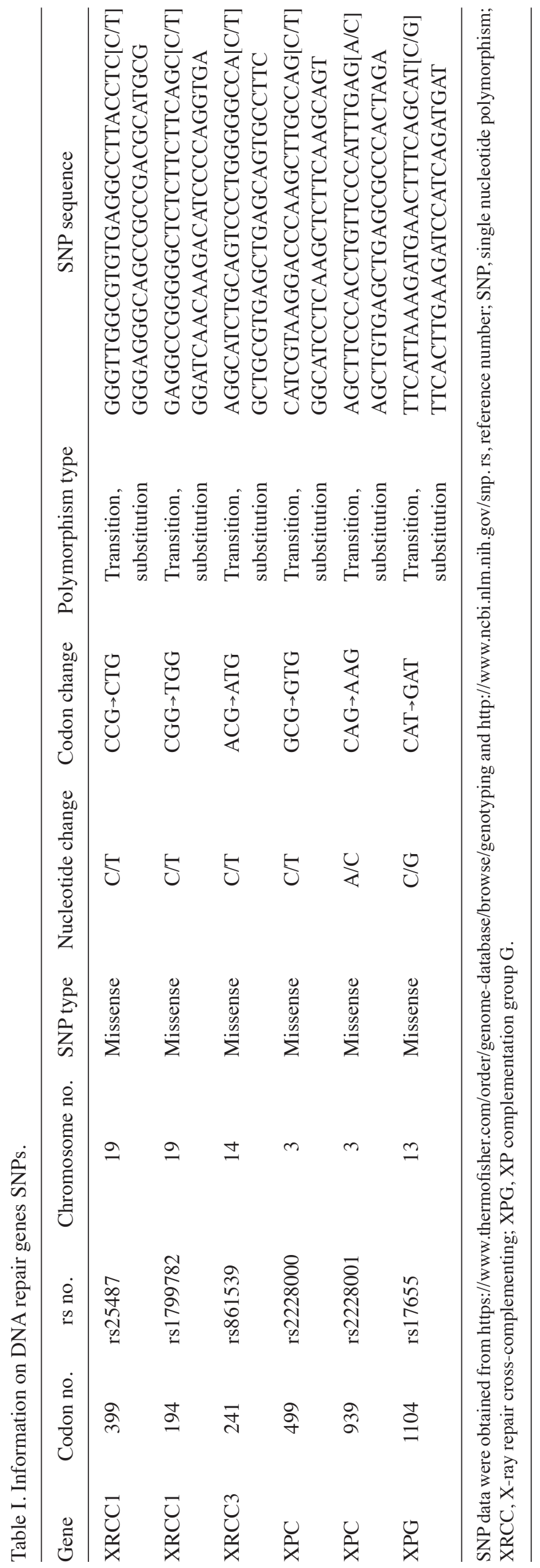

Table II. DNA repair genes single nucleotide polymorphism assay ID.

\begin{tabular}{lll}
\hline Gene & \multicolumn{1}{c}{ rs no. } & Assay ID \\
\hline XRCC1 & rs25487 & C__622564_10 \\
XRCC1 & rs1799782 & C__11463404_10 \\
XRCC3 & rs861539 & C__8901525_10 \\
XPC & rs2228000 & C_16018061_10 \\
XPC & rs2228001 & C___234284_1_ \\
XPG & rs17655 & C__1891743_10
\end{tabular}

rs, reference number; XRCC, X-ray repair cross-complementing; XPC, XP complementation group C; XPG, XP complementation group $\mathrm{G}$.

Table III. Characteristics of the classical Hodgkin's lymphoma cases at John Hopkins Aramco Healthcare Center during 1990 to 2015 .

\begin{tabular}{lrc} 
& \multicolumn{2}{c}{ Total } \\
\cline { 2 - 3 } Characteristics & $\mathrm{n}$ & $\%$ \\
\hline Age, years & 100 & - \\
$(<45)$ & 78 & 78.0 \\
$(\geq 45)$ & 27 & 27.0 \\
Sex & 100 & - \\
Male & 56 & 56.0 \\
Female & 44 & 44.0 \\
Treatment received (response) & 100 & - \\
Curative & 98 & 98.0 \\
Palliative & 2 & 2.0 \\
Relapse & 100 & - \\
No relapse & 84 & 84.0 \\
Relapse & 16 & 16.0 \\
Overall survival & 100 & - \\
Did not survive & 11 & 11.0 \\
Survived & 89 & 89.0 \\
\end{tabular}

DNA FFPE Tissue (250) kit (Qiagen GmbH, Hilden, Germany) according to the manufacturer's protocol.

Determination of concentration and purity of extracted DNA. DNA yields were determined by measuring the light absorbance at $260 \mathrm{~nm}$. The purity was determined by calculating the ratio of absorbance at $260 \mathrm{~nm}$ to absorbance at $280 \mathrm{~nm}$. Pure DNA has an A260/A280 ratio of 1.7-1.9. At $260 \mathrm{~nm}$, optimum absorbance readings should measure between 0.1 and 1.0; dilutions of the samples in the present study were adjusted accordingly.

PCR. PCR was then performed for all CHL tissue samples and controls using the 96 -well plate TaqMan ${ }^{\circledR}$ GTXpress ${ }^{\mathrm{TM}}$ Master Mix system (Applied Biosystems; Thermo Fisher 


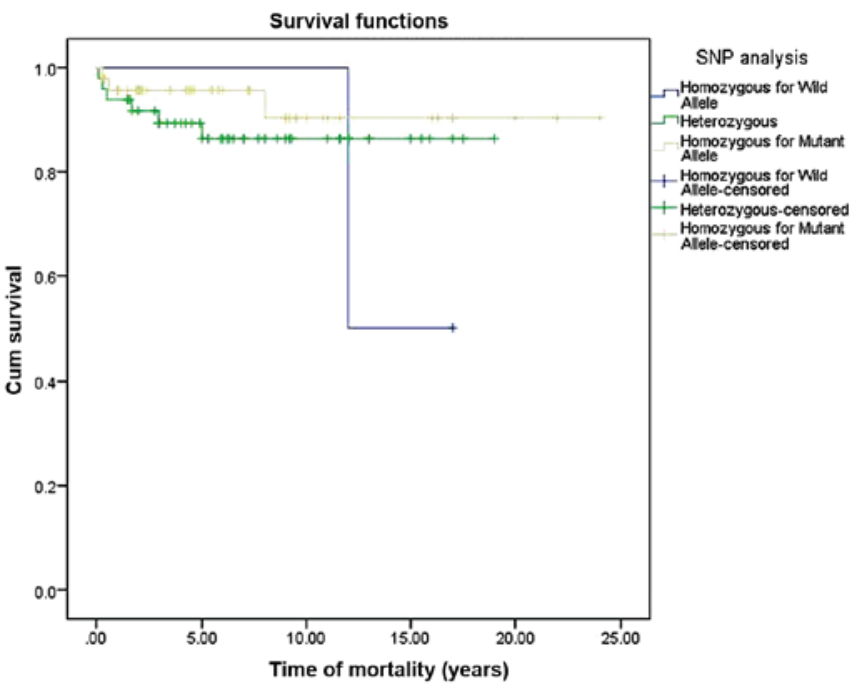

Figure 1. Estimated survival curve based on xeroderma pigmentosum complementation group G SNP analysis. SNP, single nucleotide polymorphism.

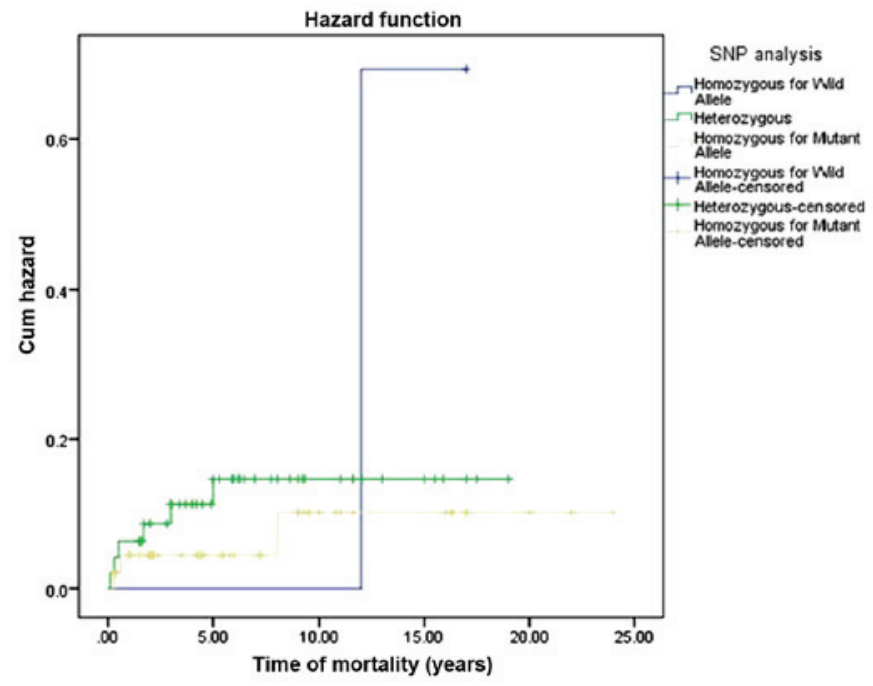

Figure 2. Estimated hazard curve based on xeroderma pigmentosum complementation group G SNP analysis. SNP, single nucleotide polymorphism.

Table IV. Allele frequencies of 4 DNA repair gene SNPs in 100 patients with classical HL and 100 controls.

\begin{tabular}{|c|c|c|c|c|c|c|c|c|c|c|c|}
\hline \multirow{2}{*}{$\begin{array}{l}\text { DNA repair } \\
\text { genes SNPs }\end{array}$} & \multirow[b]{2}{*}{ rs no. } & \multicolumn{4}{|c|}{ Allele frequency } & \multirow[b]{2}{*}{ OR } & \multirow[b]{2}{*}{ CI (95\%) } & \multirow[b]{2}{*}{$\chi^{2}$} & \multirow[b]{2}{*}{ df } & \multirow[b]{2}{*}{ P-value ${ }^{a}$} & \multirow[b]{2}{*}{ P-value ${ }^{b}$} \\
\hline & & \multicolumn{2}{|c|}{ HL patients } & \multicolumn{2}{|c|}{ Control group } & & & & & & \\
\hline \multirow[t]{2}{*}{ XRCC1 } & rs 25487 & $\mathrm{C}$ & $\mathrm{T}$ & $\mathrm{C}$ & $\mathrm{T}$ & - & - & - & - & - & - \\
\hline & & 0.76 & 0.25 & 0.78 & 0.22 & 0.87 & $0.546-1.383$ & 0.35 & 1 & 0.554 & 0.554 \\
\hline \multirow[t]{2}{*}{ XRCC1 } & rs 1799782 & $\mathrm{C}$ & $\mathrm{T}$ & $\mathrm{C}$ & $\mathrm{T}$ & - & - & - & - & - & - \\
\hline & & 0.03 & 0.97 & 0.07 & 0.93 & 0.44 & $0.16-1.94$ & 2.094 & 1 & 0.1 & 0.1 \\
\hline \multirow[t]{2}{*}{ XRCC3 } & rs861539 & $\mathrm{C}$ & $\mathrm{T}$ & $\mathrm{C}$ & $\mathrm{T}$ & & - & - & - & - & - \\
\hline & & 0.3 & 0.7 & 0.38 & 0.63 & 0.71 & $0.47-1.08$ & 2.515 & 1 & 0.113 & 0.113 \\
\hline \multirow[t]{2}{*}{ XPC } & rs2228001 & A & $\mathrm{C}$ & A & $\mathrm{C}$ & - & - & - & - & - & - \\
\hline & & 0.57 & 0.43 & 0.58 & 0.43 & 0.98 & $0.65-1.46$ & 0.01 & 1 & 0.919 & 0.919 \\
\hline \multirow[t]{2}{*}{ XPC } & rs 2228000 & $\mathrm{C}$ & $\mathrm{T}$ & $\mathrm{C}$ & $\mathrm{T}$ & - & - & - & - & - & - \\
\hline & & 0.15 & 0.86 & 0.11 & 0.89 & 1.37 & $0.75-2.48$ & 1.101 & 1 & 0.294 & 0.293 \\
\hline \multirow[t]{2}{*}{ XPG } & rs 17655 & $\mathrm{C}$ & $\mathrm{G}$ & $\mathrm{C}$ & $\mathrm{G}$ & - & - & - & - & - & - \\
\hline & & 0.28 & 0.73 & 0.43 & 0.57 & 0.5 & $0.33-0.764$ & 10.53 & 1 & 0.002 & 0.002 \\
\hline
\end{tabular}

XRCC, X-ray repair cross-complementing; XPC, XP complementation group C; XPG, XP complementation group G; rs, reference number; OR, odds ratio; CI, confidence interval; df, degrees of freedom; HL, Hodgkin's lymphoma. ${ }^{a}$ Fisher's exact test; ${ }^{\text {Pearson's }} \chi^{2}$.

Scientific, Inc., Waltham, MA, USA) according to the manufacturer's protocol. The PCR and genotyping assays were performed using the Applied Biosystems 7500 Real-Time PCR System (Applied Biosystems; Thermo Fisher Scientific, Inc.). Designed primers were produced by TaqMan ${ }^{\circledR}$ GTXpress $^{\mathrm{TM}}$ (Applied Biosystems; Thermo Fisher Scientific, Inc.) and are listed in Table II. The reaction conditions were as follows: A cycle at $95^{\circ} \mathrm{C}$ for $20 \mathrm{sec}$, followed by 40 cycles at $95^{\circ} \mathrm{C}$ for $15 \mathrm{sec}$ and $60^{\circ} \mathrm{C}$ for $60 \mathrm{sec}$.

Statistical analysis. SPSS software v.20 (IBM Corporation, Armonk, NY, USA) was used to perform all statistical analysis. The CHL disease relapse (DR) was calculated as the time from starting the treatment until disease recurrence, or relapse. The overall survival (OS) was calculated as the time from receiving the treatment until mortality. Survival curves were estimated using the Kaplan-Meier analysis method and assessed for statistical significance using the log-rank test incorporating hazard function analysis and cumulative hazard rate estimation compared with OS. Genotype and allele frequencies analysis for all studied SNPs were performed using the SHEsis software (http://analysis.bio-x.cn/myAnalysis.php) (15) and frequencies between patients and controls were assessed by Fisher's exact test and Pearson's $\chi^{2}$ test. The $\chi^{2}$ test was also used to assess association between all the studied SNPs with the disease relapse and OS of the patients with CHL. 
Table V. Summary of significant associations between DNA repair gene SNPs with DR, OS, age groups and sex of the Saudi patients with CHL at John Hopkins Aramco Healthcare Center during 1990 to 2015.

\begin{tabular}{|c|c|c|c|c|c|c|c|c|c|c|}
\hline \multirow[b]{2}{*}{ DNA repair gene SNPs } & \multicolumn{2}{|c|}{$\begin{array}{c}\text { Patients with } \\
\text { CHL }\end{array}$} & \multicolumn{2}{|c|}{$\begin{array}{l}\text { Control } \\
\text { group }\end{array}$} & \multirow[b]{2}{*}{ DR } & \multirow[b]{2}{*}{ OS } & \multirow[b]{2}{*}{ Males } & \multirow[b]{2}{*}{ Females } & \multirow{2}{*}{$\begin{array}{c}\text { Age } \\
(<45 \text { years })\end{array}$} & \multirow{2}{*}{$\begin{array}{c}\text { Age } \\
(\geq 45 \text { years })\end{array}$} \\
\hline & $\mathrm{n}$ & $\%$ & $\mathrm{n}$ & $\%$ & & & & & & \\
\hline XRCC1 (rs25487) & 100 & - & 100 & - & 0.696 & 0.275 & - & - & - & - \\
\hline Hom for $\mathrm{Wt}$ allele & 55 & 55 & 62 & 62 & - & - & - & - & - & - \\
\hline Het & 41 & 41 & 32 & 32 & - & - & - & - & - & - \\
\hline Hom for Mut allele & 4 & 4 & 6 & 6 & - & - & - & - & - & - \\
\hline XRCC1 (rs1799782) & 100 & & 100 & & 0.32 & 0.504 & - & - & - & - \\
\hline Hom for $\mathrm{Wt}$ allele & 1 & 1 & 0 & 0 & - & - & - & - & - & - \\
\hline Het & 4 & 4 & 13 & 13 & - & - & - & - & - & - \\
\hline Hom for Mut allele & 95 & 95 & 87 & 87 & - & - & - & - & - & - \\
\hline XRCC3 (rs861539) & 100 & & 100 & & 0.207 & 0.519 & - & - & - & - \\
\hline Hom for $\mathrm{Wt}$ allele & 12 & 12 & 11 & 11 & - & - & - & - & - & - \\
\hline Het & 36 & 36 & 53 & 53 & - & - & - & - & - & - \\
\hline Hom for Mut allele & 52 & 52 & 36 & 36 & - & - & - & - & - & - \\
\hline XPC (rs2228001) & 100 & - & - & - & 0.572 & 0.078 & - & - & - & - \\
\hline Hom for Wt allele & 29 & 29 & 30 & 30 & - & - & - & - & - & - \\
\hline Het & 56 & 56 & 55 & 55 & - & - & - & - & - & - \\
\hline Hom for Mut allele & 15 & 15 & 15 & 15 & - & - & - & - & - & - \\
\hline XPC (rs2228000) & 100 & - & 100 & - & 0.885 & 0.449 & - & - & - & - \\
\hline Hom for Wt allele & 1 & 1 & 2 & 2 & - & - & - & - & - & - \\
\hline Het & 27 & 27 & 18 & 18 & - & - & - & - & - & - \\
\hline Hom for Mut allele & 72 & 72 & 80 & 80 & - & - & - & - & - & - \\
\hline XPG (rs17655) & 100 & - & 100 & - & 0.078 & 0.036 & 0.034 & 0.159 & 0.415 & 0.41 \\
\hline Hom for Wt allele & 2 & 2 & 18 & 18 & - & - & - & - & - & - \\
\hline Het & 51 & 51 & 50 & 50 & - & - & - & - & - & - \\
\hline Hom for Mut allele & 47 & 47 & 32 & 32 & - & - & - & - & - & - \\
\hline
\end{tabular}

Hom, homozygous; Het, heterozygous; Wt, wild-type; Mut, mutant SNP, single nucleotide polymorphism; DR< disease relapse; OS, overall survival; rs, reference number.

\section{Results}

Demographic characteristics of CHL patients at JHAH. A review of the records at JHAH indicated that CHL represented $>85 \%$ of the HL cases diagnosed during the study period. The study population comprised 56 males and 44 females, with a male: female ratio of 1.3:1. The age of the patients ranged from 3-80 years, with a median age of 42 years. In addition, $78 \%$ of the patients with $\mathrm{CHL}$ were $<45$ years old (Table III). The data from the study population indicated that 27/100 (27\%) patients were $\geq 45$ years old.

Furthermore, a total of 16 CHL patients (16\%) had relapsed within the median period of 3.2 years, whilst 11 patients $(11 \%)$ had succumbed from the disease within the same period. The majority of the patients with CHL succumbed within the first 5 years, with an OS median of 3.5 years.
XPG allele frequency analysis. The allele frequency analysis revealed that the XPG repair gene SNP polymorphism rs17655 $(\mathrm{C} / \mathrm{G})$ demonstrated a significant difference in allele frequency distribution between the patients with CHL and the healthy controls $(\mathrm{P}=0.002)$. However, the OR calculated for the wild allele $(\mathrm{C})$ was low $[\mathrm{OR}=0.50 ; 95 \%$ confidence interval $(\mathrm{CI})$, 0.33-0.764; Table IV].

DNA repair genes association with DR and OS. $\chi^{2}$ analysis of the 3 allele genotype patterns of the DNA repair genes SNPs revealed that there is no statistically significant association between any of the studied SNPs with CHL DR or OS, with the exception of XPG SNP (rs17655), which demonstrated statistical significance with the OS of the patients with $\mathrm{CHL}$ $(\mathrm{P}=0.036)$ but not with DR. It was also identified that this association was independent of patient age $(\mathrm{P}=0.415)$; by contrast, 
XPG SNP was demonstrated to be significantly associated with the male sex $(\mathrm{P}=0.034$; Table $\mathrm{V})$.

In addition, analysis of the effect of different SNPs combinations was considered in the present study. No significant association with DR or OS in the patients with CHL was observed during the combined analysis of XPG with all other studied SNP polymorphisms, with the exception of the combination of XPG (rs17655)/XRCC1 (rs1799782), for which a significant association with the OS of CHL was identified $(\mathrm{P}=0.026)$.

Survival curve estimation based on XPG SNP analysis. The survival curve was estimated for the XPG SNP using the Kaplan-Meier analysis method. Accordingly, an observable decrease in the OS function of the patients with CHL, with statistical significant log-rank test $(\mathrm{P}=0.0361)$, considerably with presence of homozygosity for wild allele (Fig. 1). Consequently, the hazard function analysis indicated an increased cumulative hazard rate with the different genotyping pattern of XPG SNP in association with CHL OS (Fig. 2). However, the estimated mean OS in patients with CHL with XPG SNPs was 21 years (95\% CI, 19-23).

\section{Discussion}

The results from the present study suggested that common DNA polymorphisms of DNA repair genes and their association with HL disease progression and patient survival may be used as predictive biomarkers. Furthermore, they may assist in the identification of a curative therapy for CHL, or to improve the current protocols. The present study highlighted the requirement for establishing a molecular profile for CHL in a mixed population, for example that of Saudi Arabia.

The primary aim of the present study was to identify a SNP-based molecular profile, using DNA repair genes mutations, which may assist in evaluating prognostic statuses and be used as prognostic biomarker in CHL. The presence of selected DNA repair gene polymorphisms in CHL was demonstrated to have an association with the risk of the disease. In addition, the interaction between DNA repair pathways was hypothesized to contribute to the HL clinical outcome. Although the prognostic significance of the DNA repair genes remains unclear, a number of retrospective reviews suggested that genetic polymorphisms of certain DNA repair genes may have a role in modifying the risk of HL $(4,11)$. In the present study 5 DNA repair genes were selected, which were confirmed to be associated with HL risk, and the association between these genes SNPs and CHL prognosis was examined in the study population.

Analysis of the allele frequency distribution of the repair gene SNPs in CHL tissues and normal controls indicated that there was a significant difference in allele frequencies of the XPG repair gene polymorphism (rs17655) between patients with CHL and the healthy controls $(\mathrm{P}=0.002)$, besides its low $\mathrm{OR}(\mathrm{OR}=0.50)$. This $\mathrm{OR}$ estimates that the relative risk of developing $\mathrm{HL}$ in the patient group with XPG nucleotide $\mathrm{C}$ SNP is $50 \%$, compared with in those patients with the G nucleotide. In addition, in comparison with other DNA repair genes SNPs, XPG may be a useful predictive indicator for the risk of HL.
Using the $\chi^{2}$ test, no statistical significance between any of the DNA repair gene genotyping expression levels and the DR was observed: XRCC1 rs25487 ( $\mathrm{P}=0.696)$; XRCC1 rs1799782 $(\mathrm{P}=0.320) ; \mathrm{XRCC} 3(\mathrm{P}=0.207) ; \mathrm{XPC}$ rs2228001 ( $\mathrm{P}=0.572)$; $\mathrm{XPC}$ rs2228000 $(\mathrm{P}=0.885)$; and XPG $(\mathrm{P}=0.078)$. Analysis of the association between the expression levels of these DNA repair genes with the OS rate demonstrated that only the XPG SNP (rs17655) was significantly associated with OS ( $\mathrm{P}=0.036)$. Regarding the results of the allele frequency analysis of the XPG gene, a significant difference in expression levels of the XPG gene among the patients with CHL compared with the healthy controls was observed. In addition, the association between the XPG SNP and CHL survival was demonstrated to be independent of age, yet it was identified to be modified by the sex of the patients with CHL. A combined analysis of XPG/XRCC1 SNPs exhibited a significant association with CHL OS in the Saudi patient population. In light of the statistically significant association between XPG SNPs and CHL patient survival, the data from the present study suggest a potential use of XPG expression analysis as a single predictive molecular biomarker for CHL clinical prognosis. To the best of our knowledge, the present study is the first to describe an association between molecular genetic patterns and HL in patients from Saudi Arabia.

In conclusion, it was demonstrated that the XPG repair gene (rs17655) SNP had a detrimental effect on CHL OS. Therefore, the XPG repair gene may be a useful predictive genetic biomarker for CHL clinical outcome in Saudi patients. These data may provide a novel avenue for the improvement of the clinical management of patients with CHL, through molecular analyses for DNA repair gene expression, which may lead to improving therapeutic protocols. However, a well-designed multi-center prospective study with a larger number of subjects and controls is recommended.

\section{Acknowledgements}

The authors would like to thank colleagues at the Arabian Gulf University and at Johns Hopkins Aramco Healthcare who provided technical assistance and efficient support. In addition, special thanks are given to Dr Ahmed Alsagheir and Dr Adel Alkhatti from the Oncology Center at Johns Hopkins Aramco Healthcare.

\section{Funding}

The present study was supported by Arabian Gulf University, College of Medicine and Medical Sciences, Kingdom of Bahrain (grant no. 36-PI-01/15).

\section{Availability of data and materials}

The analyzed data sets generated during the study are available from the corresponding author on reasonable request.

\section{Authors' contributions}

HASA and WFR designed the experiments. HASA wrote the manuscript, performed the experiments, validation and analysis. WFR, AHSD and MDF reviewed and revised the 
manuscript and AHSD acquired funding. All authors have read and approved the final manuscript.

\section{Ethics approval and consent to participate}

The appropriate research ethical approval for the research and informed consent was obtained all patients providing tissues and blood samples.

\section{Patient consent for publication}

Written informed consent was obtained from the patients, guardians or next of kin for deceased patients, as appropriate, for the publication of any associated data.

\section{Competing interests}

The authors declare that they have no competing interests.

\section{References}

1. Rauf MS, Akhtar S and Maghfoor I: Changing trends of adult lymphoma in the Kingdom of Saudi Arabia - comparison of data sources. Asian Pac J Cancer Prev 16: 2069-2072, 2015.

2. Leukemia and Lymphoma Society: American Cancer Society Cancer Facts \& Figures 2016; GLOBOCAN 2012; ClinicalTrials. gov; CRI grantee progress reports and other CRI grantee documents, 2016.

3. Kron KJ, Bailey SD and Lupien M: Enhancer alterations in cancer: A source for a cell identity crisis. Genome Med 6: 77, 2014.

4. Monroy CM, Cortes AC, Lopez M, Rourke E, Etzel CJ, Younes A, Strom SS and El-Zein R: Hodgkin lymphoma risk: Role of genetic polymorphisms and gene-gene interactions in DNA repair pathways. Mol Carcinog 50: 825-834, 2011.
5. Al-Madouj AN, Eldali A and Al-Zahrani AS: Ten Year Cancer Incidence among nationals of the GCC states 1998-2007. Gulf Center for Cancer Control and Prevention, King Faisal Specialist Hospital and Research Center. Riyadh, 2011.

6. Fitzmaurice C, Allen C, Barber RM, Barregard L, Bhutta ZA, Brenner H, Dicker DJ, Chimed-Orchir O, Dandona R, Dandona L, et al: Global, regional, and national cancer incidence, mortality, years of life lost, years lived with disability, and disability-adjusted life-years for 32 cancer groups, 1990 to 2015: A Systematic Analysis for the Global Burden of Disease Study. JAMA Oncol 3: 524-548, 2017.

7. Al-Diab AI, Siddiqui N, Sogiawalla FF and Fawzy EM: The changing trends of adult Hodgkin's disease in Saudi Arabia. Saudi Med J 24: 617-622, 2003

8. Maggioncalda A, Malik N, Shenoy P, Smith M, Sinha R and Flowers CR: Clinical, molecular, and environmental risk factors for hodgkin lymphoma. Adv Hematol 2011: 736261, 2011.

9. Scott DW and Steidl C: The classical Hodgkin lymphoma tumor microenvironment: Macrophages and gene expression-based modeling. Hematology Am Soc Hematol Educ Program 2014: 144-150, 2014.

10. Sud A, Hemminki K and Houlston RS: Candidate gene association studies and risk of Hodgkin lymphoma: A systematic review and meta-analysis. Hematol Oncol 35: 34-50, 2017.

11. El-Zein R, Monroy CM, Etzel CJ, Cortes AC, Xing Y, Collier AL and Strom SS: Genetic polymorphisms in DNA repair genes as modulators of Hodgkin disease risk. Cancer 115: 1651-1659, 2009.

12. Piccaluga PP, Agostinelli C, Gazzola A, Tripodo C, Bacci F, Sabattini E, Sista MT, Mannu C, Sapienza MR, Rossi M, et al: Pathobiology of Hodgkin lymphoma. Adv Hematol 2011: 920898, 2011.

13. Smith LB: Nodular lymphocyte predominant Hodgkin lymphoma: Diagnostic pearls and pitfalls. Arch Pathol Lab Med 134: 1434-1439, 2010.

14. Carbone PP, Kaplan HS, Musshoff K, Smithers DW and Tubiana M: Report of the Committee on Hodgkin's disease staging classification. Cancer Res 31: 1860-1861, 1971.

15. Shi YY and He L: SHEsis, a powerful software platform for analyses of linkage disequilibrium, haplotype construction, and genetic association at polymorphism loci. Cell Res 15: 97-98, 2005 . 